\title{
2017 CIPHI Awards
}

The 2017 CIPHI Awards were handed out during the most recent National AGM in November in Richmond, British Columbia. Congratulations to all the winners!

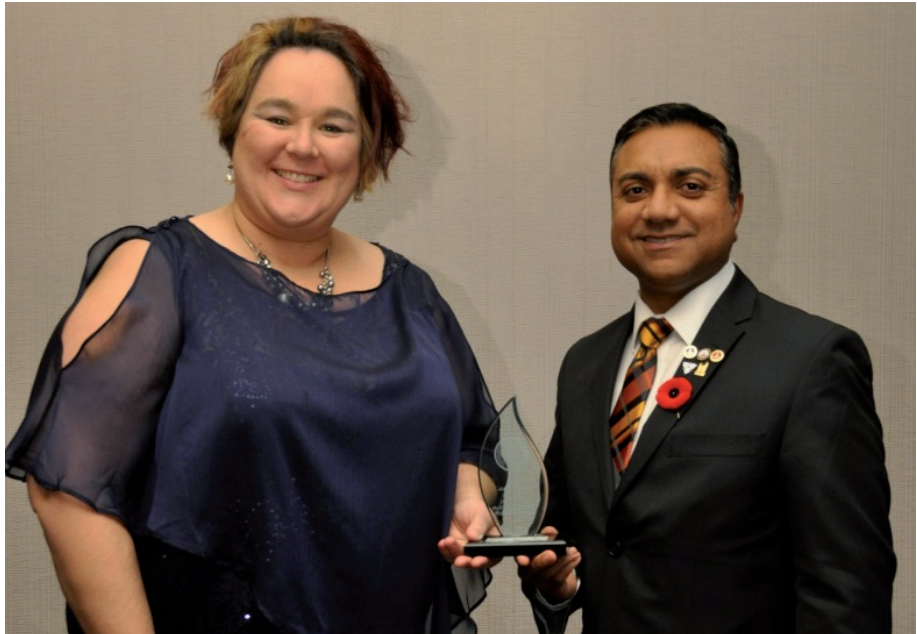

Raymond Ramydayal (ON Branch President) accepting the Alex Cross award on behalf of Catherine Egan (ON). Presented by Kari Engele-Carter (CIPHI President-Elect).

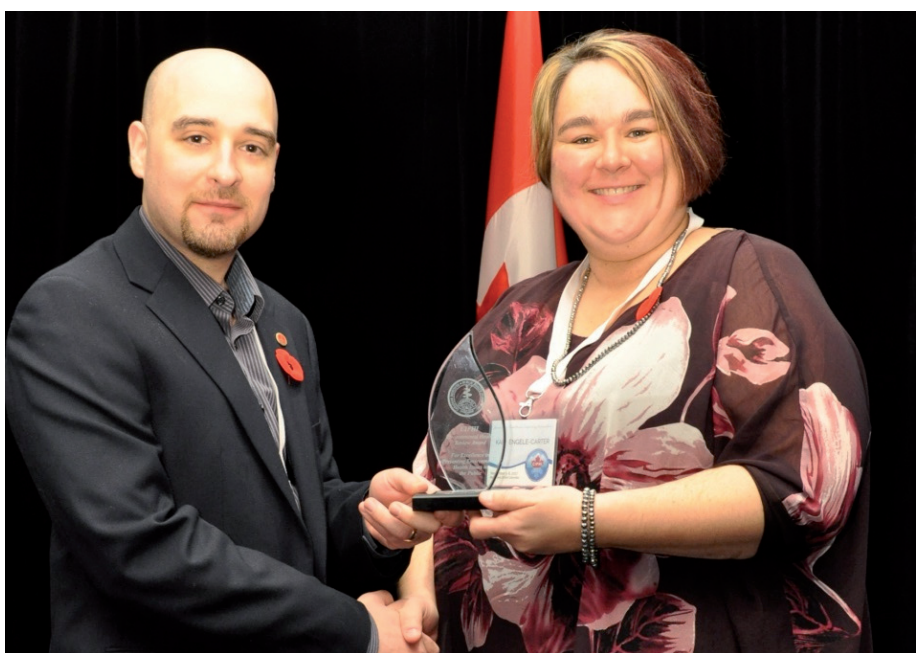

Greggory Barrett (NL President) accepts the EHR award on behalf of Sharon Williams (NL). Presented by Kari Engele-Carter (CIPHI President-Elect)

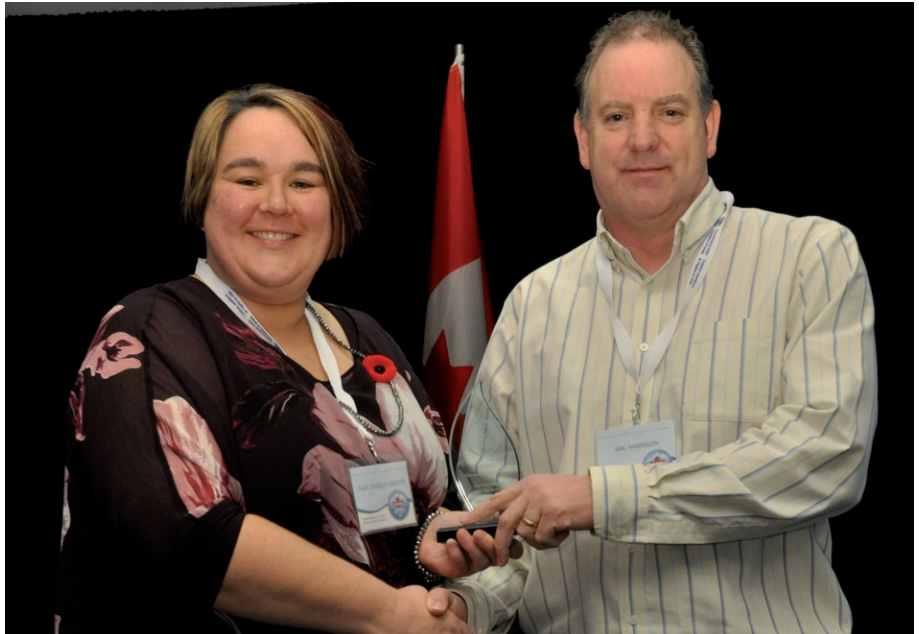

Ian Harrison accepting the Alexander Officer Award on behalf of the SEHIP Task Group (SK) (Saskatchewan Environmental Health Inspection Program Task Group). Presented by Kari Engele-Carter (CIPHI President-Elect).

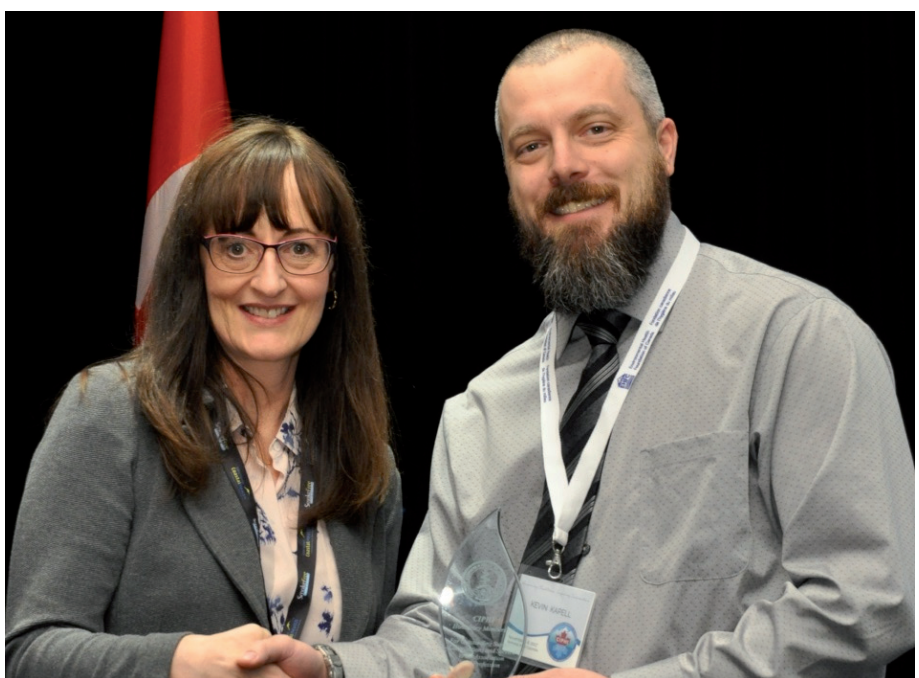

Kevin Kapell (SK Branch President) presents the Honorary Membership Award to Patricia Daly (BC) 


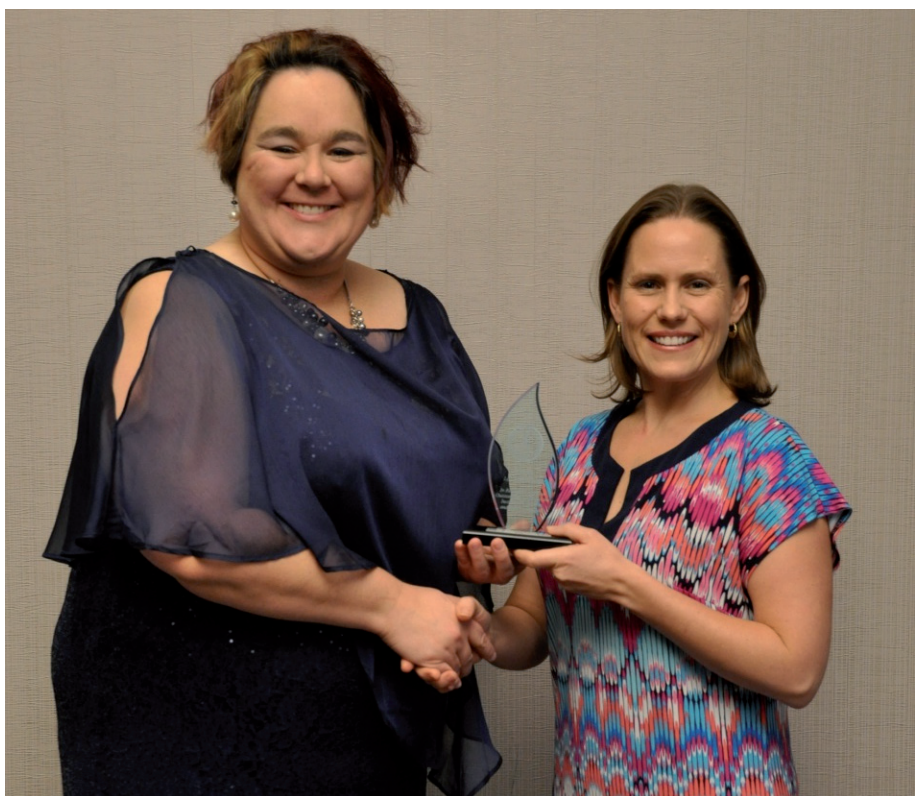

Kari Engele-Carter (CIPHI President-Elect) presents the Life Membership Award. Accepting for Kenneth Christian is Courtney Hesketh, Director of Environmental Public Health for Interior Health.

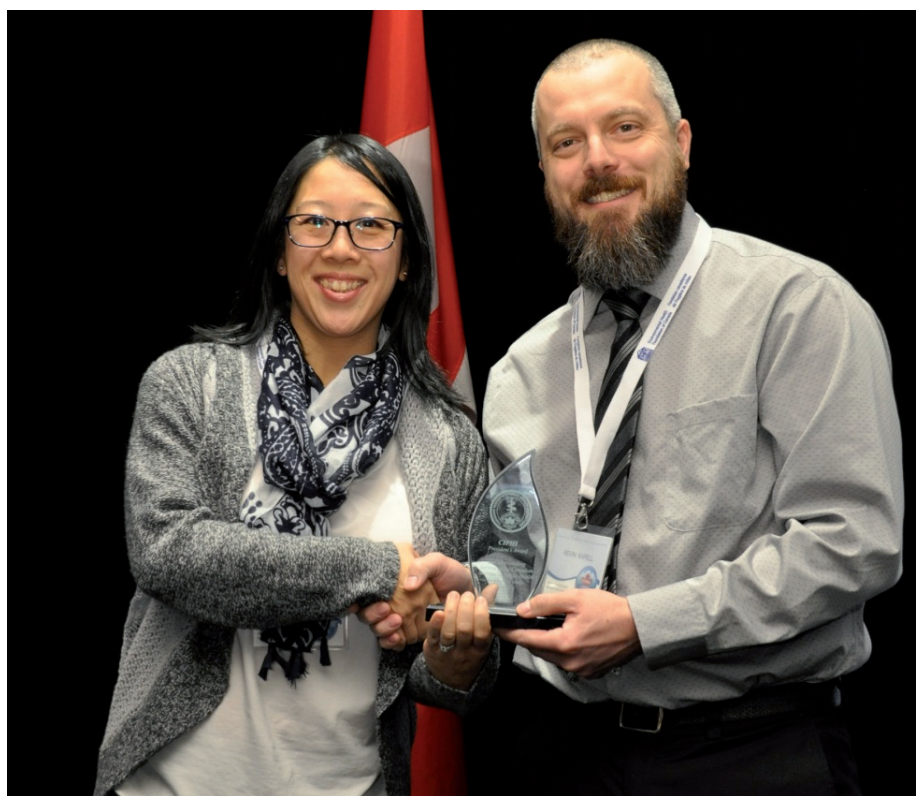

Kevin Kapell (SK President) presents the President's Award to Craig Nowakowski (BC). Accepting on Craig's behalf is Joanne Lum, Team Leader with Island Health. 